\title{
Synergistic cytotoxic effects of recombinant human adenovirus p53 and radiation at various time points in A549 lung adenocarcinoma cells
}

\author{
JIE-TAO MA, CHENG-BO HAN, JIAN-ZHU ZHAO, WEI JING, YANG ZHOU, \\ LE-TIAN HUANG and HUA-WEI ZOU
}

Department of Oncology, Shengjing Hospital of China Medical University, Shenyang, Liaoning 110022, P.R. China

Received February 20, 2012; Accepted May 31, 2012

DOI: $10.3892 / \mathrm{ol} .2012 .747$

\begin{abstract}
The aim of this study was to evaluate the effects of recombinant human adenovirus p53 (rAd-p53; Gendicine) transfection and radiation at various time points following transfection. Cytotoxic effects and p53 protein expression levels were analyzed. rAd-p53 containing the human wild-type p53 gene was introduced into the human lung adenocarcinoma cell line A549, and cells were irradiated with a single dose of $6 \mathrm{MeV} 4 \mathrm{~Gy} \beta$ rays. According to the time interval between rAd-p53 transfection and radiotherapy (RT), A549-transfected rAd-p53 cells were divided into 5 groups: radiation administered immediately after transfection (0 h-RT) group, after $3 \mathrm{~h}$ group (3 h-RT), after 6 h group (6 h-RT), after 24 h group ( 24 h-RT) and after $48 \mathrm{~h}$ group ( $48 \mathrm{~h}-\mathrm{RT})$. Cells with rAd-p53 transfection alone (Ad-p53) and with empty adenovirus (Ad) were included as the two control groups. Following $72 \mathrm{~h}$ of transfection, cell viability and growth were analyzed using MTT assays and flow cytometry, and p53 protein expression was analyzed using western blot analysis. From 0 h-RT to 48 h-RT, cell viability gradually decreased, while percentage of apoptotic cells and p53 protein expression gradually increased. The cell viability suppression rates in the $6 \mathrm{~h}-\mathrm{RT}, 24 \mathrm{~h}-\mathrm{RT}$ and $48 \mathrm{~h}$-RT groups were $56.7 \pm 5.4,60.8 \pm 6.0$ and $68.9 \pm 6.6$, respectively, which were significantly greater compared to that of the Ad-p53

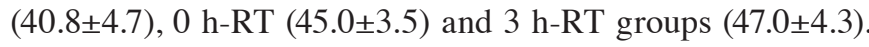
No statistically significant differences were observed in the cell viability suppression rates among the 6 h-RT, 24 h-RT and 48 h-RT groups $(\mathrm{P}>0.05)$. Similar changes were observed in the percentage of apoptotic cells. The p53 protein expression level in the $6 \mathrm{~h}-\mathrm{RT}$ group $(0.856 \pm 0.092)$ was higher compared to that in the $3 \mathrm{~h}-\mathrm{RT}$ group $(0.643 \pm 0.089)(\mathrm{t}=2.882 ; \mathrm{P}=0.045)$, but not significantly different from that of the 24 h-RT
\end{abstract}

Correspondence to: Professor Cheng-Bo Han, Department of Oncology, Shengjing Hospital of China Medical University, Shenyang, Liaoning 110022, P.R. China

E-mail: hancb@126.com; doctor.hancb@gmail.com

Key words: adenovirus p53, radiation therapy, gene therapy group (1.193 \pm 0.202$)$. The cell viability suppression rate and percentage of apoptotic cells was positively correlated with p53 protein expression in the A549 cells $(\mathrm{P}<0.05)$. Radiation may inhibit or damage $\mathrm{p} 53$ protein expression at the early stage of rAd-p53 transfection. To sensitize tumor cells to irradiation and achieve maximal cytotoxic effects, it is recommended to conduct RT at least $6 \mathrm{~h}$ following transfection with rAd-p53.

\section{Introduction}

The wild-type p53 gene (wt-p53), an important tumor suppressor gene, is a key regulatory factor determining cell survival during the cellular stress response to radiation-induced DNA damage. DNA damage responses trigger a series of chemical modifications, including p53 phosphorylation. Activated p53 transcription promotes or inhibits expression of downstream genes, thereby causing cell cycle arrest, DNA repair and tumor cell apoptosis through the regulation of target genes $(1,2)$. To date, dysfunction of tumor suppressor genes has been confirmed as the most significant genetic damage in human cancers. Mutations or deletions of p53 occur in 50-70\% of non-small cell lung cancers (NSCLCs) and are associated with poor prognosis of lung cancer patients $(3,4)$.

A previous study demonstrated that patients with wt-p53 with loss of function were less sensitive to radiotherapy (5). In vivo and in vitro studies have revealed that wt-p53 transfection in combination with radiotherapy (RT) may increase the sensitivity to low linear energy transfer (LET) radiation (6-8); although mutant p53 may respond well to high LET radiation $(9,10)$. Recombinant human adenovirus (Ad) p53 injection (rAd-p53; trade name, Gendicine) is a gene therapy administered intratumorally, which uses type 5 Ad to carry the recombinant human p53 gene. Transfection of Ad is able to introduce the p53 gene into tumor cells to express wt-p53 protein, which may execute its functions in inhibiting cell division and inducing tumor cell apoptosis. Combination therapy of rAd-p53 and radiation has demonstrated good efficacy for the treatment of multiple tumors. It has also been approved as a treatment model for certain head and neck malignancies, including nasopharyngeal carcinoma (11). Previous studies have revealed that the peak time for wt-p53 expression following Gendicine treatment was 48-72 h after transfection (12-14). 
Therefore, Gendicine administration twice a week helps to achieve a stable expression platform of wt-p53 proteins. The time of rAd-p53 transfection may overlap with at least one of five-weekly standard RT treatments. However, whether RT may affect the expression of exogenous wt-p53 mediated by Ad, and what the optimal interval between radiation and rAd-p53 treatment is remains unclear.

This study introduced rAd-p53 containing the human wt-p53 gene into the human lung adenocarcinoma cell line A549. RT was applied at various time points following gene transfection in order to evaluate the effect of combination therapy on growth inhibition, cell apoptosis and $\mathrm{p} 53$ protein expression. Our aim was to explore the optimal interval time of RT following rAd-p53 transfection, in order to obtain maximum clinical effects.

\section{Materials and methods}

Materials. Human lung adenocarcinoma cell line A549 was obtained from the Biological Testing Center of the Cancer Hospital (Chinese Academy of Medical Sciences, Beijing, China), RPMI-1640 culture medium from Gibco (Carlsbad, CA, USA) and $15 \%$ fetal bovine serum (FBS) from Hyclone Laboratories Inc., (Logan, UT, USA). The MTT assay was obtained from Sigma (St. Louis, MO, USA), Hoechst 33342/propidium iodide (PI) double-staining kit from GenScript (USA Inc., Piscataway, NJ, USA) and total protein extraction kit from, Nanjing KeyGene Biotechnology Co., Ltd., (Nanjing, China). We obtained the concentrated mouse anti-human p53 monoclonal antibody (1:1000) from Abcam (Cambridge, MA, USA), the ready to use mouse anti-human $\beta$-actin monoclonal antibody (1:1000) from Santa Cruz Biotechnology Inc., (Santa Cruz, CA, USA), goat anti-mouse IgG antibody (1:2000) from Beijing Zhongshan Golden Bridge Biotechnology Co., (Beijing, China), human Ad type 5 from Vector BioLabs (Philadelphia, PA, USA) and the recombinant human p53 Ad injection (rAd-p53 injection; trade name, Gendicine; lot number, 20090514; $10^{12}$ viral particles/vial, $2 \mathrm{ml} / \mathrm{vial}$ ) from Shenzhen Sibiono Gene Technology Co., Ltd. (Shenzhen, China). Plaque assay determined the titer as $1 \times 10$ plaque forming unit (PFU)/ vial.

Cell culture. RPMI-1640 culture medium containing $300 \mu \mathrm{g} / \mathrm{ml}$ glutamine, $100 \mathrm{U} / \mathrm{ml}$ penicillin, $100 \mu \mathrm{g} / \mathrm{ml}$ streptomycin and 15\% FBS was used. A549 cells were cultured in a $37^{\circ} \mathrm{C}, 5 \% \mathrm{CO}_{2}$ and $95 \% \mathrm{O}_{2}$ incubator and those at exponential growth phase were selected for further study.

Irradiation. A $6 \mathrm{MeV}$ medical linear accelerator (Siemens Primus, Erlangen, German) was used with a $100 \mathrm{~cm}$ source skin distance, $0.5 \mathrm{~cm}$ tissue equivalent compensator, $300 \mathrm{cGy} / \mathrm{min}$ dose rate and a 4 Gy single dose.

Treatment and grouping. A549 cells at exponential growth phase were cultured in serum-free culture medium for $12 \mathrm{~h}$ for cell cycle synchronization, and cultured for a further $24 \mathrm{~h}$. Following cell attachment, $1 \times 10^{10} \mathrm{VP} /$ well rAd-p53 injection was added into each group (to infect cells at $1000 \mathrm{PFU} / \mathrm{cell}$ ), and an equal volume of culture medium was added into the control group. According to the time between rAd-53 transfection and RT, cells

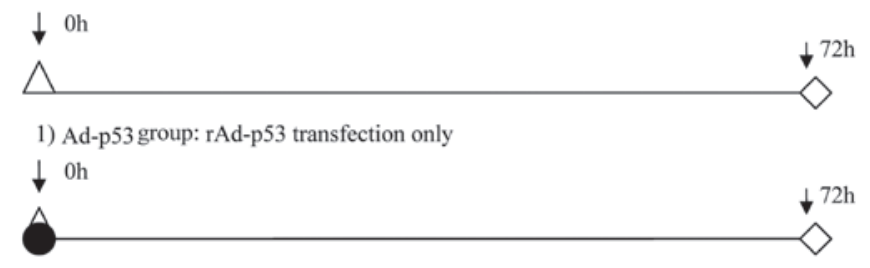

2) Oh-RT group: rAd-p53 transfection and immediate radiation group

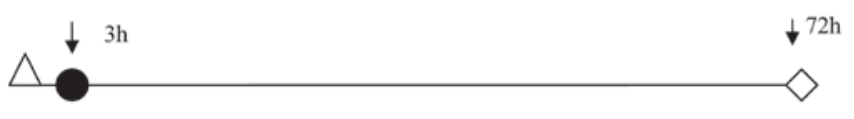

3) 3h-RT group: rAd-p53 transfection and radiation at $3 \mathrm{~h}$ group

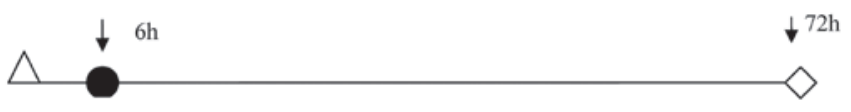

4) 6h-RT group: rAd-p53 transfection and radiation at $6 \mathrm{~h}$ group

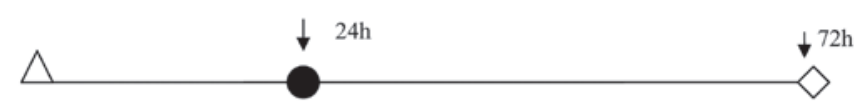

5) 24h-RT group: rAd-p53 transfection and radiation at $24 \mathrm{~h}$ group

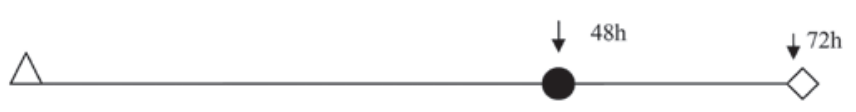

6) $48 \mathrm{~h}-\mathrm{RT}$ group: rAd-p 53 transfection and radiation at $48 \mathrm{~h}$ group

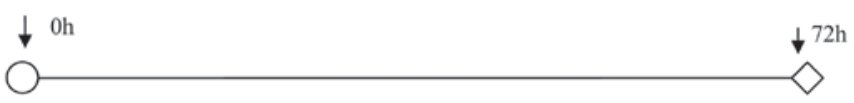

7) Ad control

Figure 1. Experimental groups based on various time points between rAd-p53 transfection and RT. $\triangle$, time points of rAd-p53 transfection; $\bullet$, time points of 4 Gy radiation; $\diamond$, time points of conducting MTT, flow cytometry and p53 protein in western blot analysis; $\bigcirc$, time points of PBS buffer addition. rAd-p53, recombinant human adenovirus p53; RT, radiotherapy; MTT, 3-(4,5-dimethylthiazol-2-yl)2,5-diphenyl tetrazolium bromide; PBS, phosphate buffered saline.

were divided into 5 groups: radiation administered immediately following transfection ( $0 \mathrm{~h}-\mathrm{RT})$ group, after $3 \mathrm{~h}$ group ( $3 \mathrm{~h}-\mathrm{RT})$, after $6 \mathrm{~h}$ group ( $6 \mathrm{~h}-\mathrm{RT})$, after $24 \mathrm{~h}$ group ( $24 \mathrm{~h}-\mathrm{RT})$ and after $48 \mathrm{~h}$ group (48 h-RT). Cells with rAd-p53 transfection alone (Ad-p53) or with the empty Ad vector transfection (Ad group) were included as the two control groups. Cells of all groups were cultured until $72 \mathrm{~h}$ following transfection and were then subjected to 3-(4,5-dimethylthiazol-2-yl)2,5-diphenyl tetrazolium bromide (MTT) assay, flow cytometry and western blot analysis, respectively (Fig. 1).

MTT assay. Following corresponding treatments, cells $\left(2 \times 10^{3 /}\right.$ well) were plated in 96-well culture plates and MTT ( $5 \mathrm{~g} / \mathrm{l})$ solution was added into each well and cultured for a further $4 \mathrm{~h}$. The supernatant was discarded from each well and $200 \mu$ l dimethyl sulfoxide was added. Following $10 \mathrm{~min}$ of agitation, absorbance at $490 \mathrm{~nm}$ was measured on a microplate reader and the growth inhibition rate was calculated as follows: Growth inhibition rate $=[(\mathrm{A}$ value of the control group $-\mathrm{A}$ value of the experimental group) / A value of the control group] x 100\%. Results are demonstrated as the mean \pm standard deviation (SD).

Flow cytometry. Following corresponding treatments, cells were harvested, adjusted to a cell density of $1 \times 10^{6}$ cells $/ \mathrm{ml}$ 
Table I. Effects of rAd-p53 transfection and radiation at various time points in A549 cells.

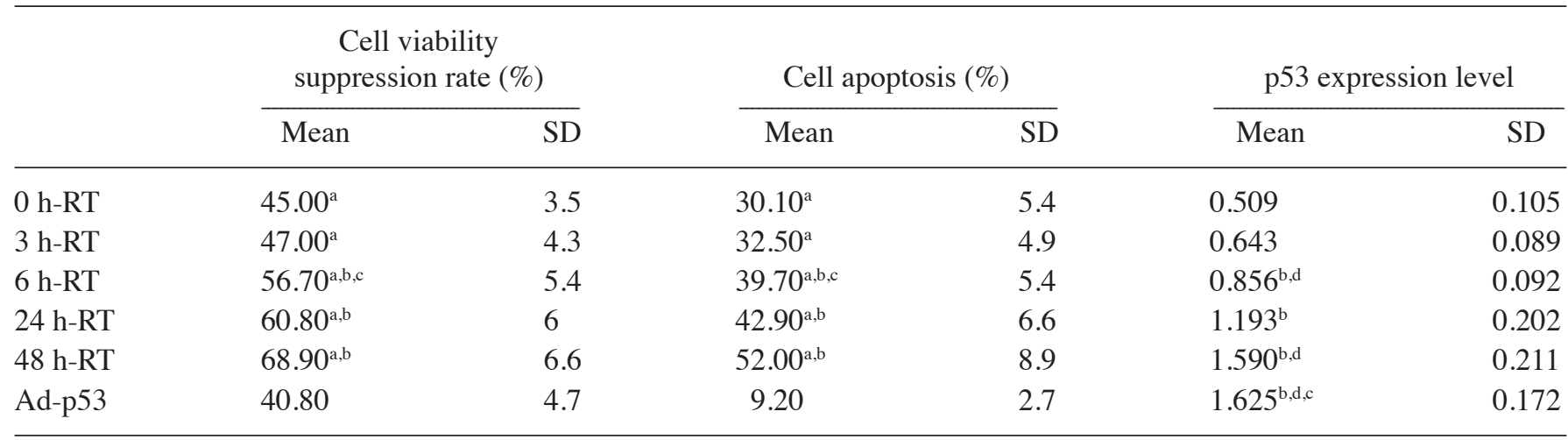

${ }^{\mathrm{a}} \mathrm{P}<0.05$ vs. Ad-p53; ${ }^{\mathrm{P}}<0.05$ vs. 0 h-RT or $3 \mathrm{~h}-\mathrm{RT}$; ${ }^{\mathrm{c}} \mathrm{P}>0.05$ vs. 48 h-RT; ${ }^{\mathrm{d}} \mathrm{P}>0.05$ vs. 24 h-RT. rAd-p53, recombinant human adenovirus p53; $\mathrm{SD}$, standard deviation; RT, radiotherapy.

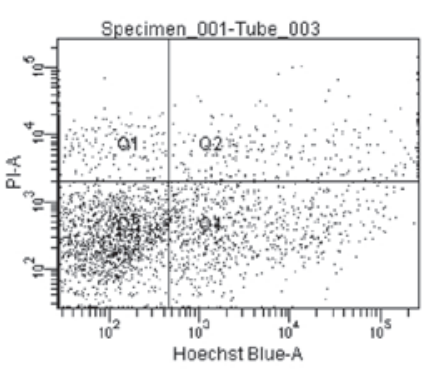

Ad-p53

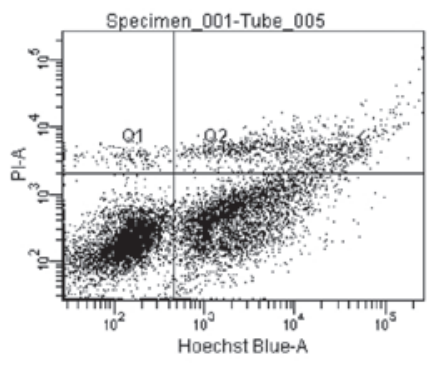

$6 \mathrm{~h}-\mathrm{RT}$

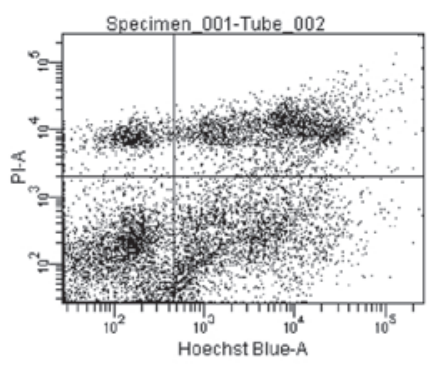

0 h-RT

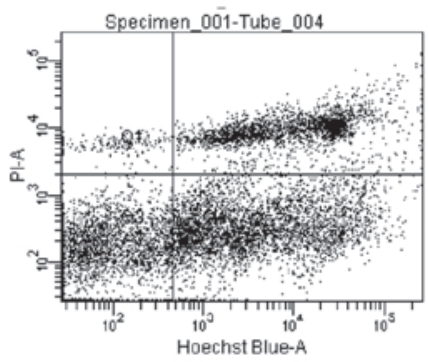

24 h-RT

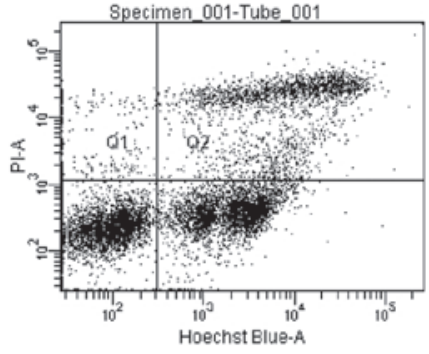

$3 \mathrm{~h}-\mathrm{RT}$

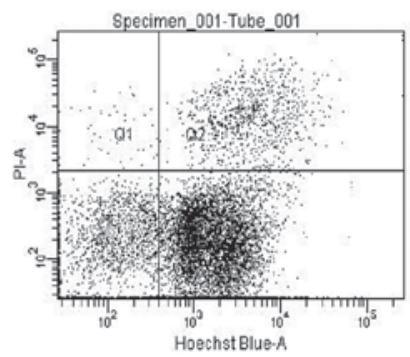

48 h-RT

Figure 2. Flow cytometry assay of cell apoptosis at various radiation time points following rAd-p53 transfection in A549 cells. rAd-p53, recombinant human adenovirus p53; RT, radiotherapy.

and incubated with Hoechst 33342 dye at $37^{\circ} \mathrm{C}$ for $10 \mathrm{~min}$. Cells were centrifuged at $1000 \mathrm{rpm}$ for $5 \mathrm{~min}$ at $4^{\circ} \mathrm{C}$ and then the supernatant was discarded. Following this, cells were incubated with PI at room temperature for $10 \mathrm{~min}$ and the stained cells were immediately analyzed using flow cytometry with UV/488 nm dual excitation. The fluorescence emission of Hoechst 33342 at $460 \mathrm{~nm}$ and PI at $640 \mathrm{~nm}$ emission were measured.

Western blot analysis. Following corresponding treatments, cells in each group were homogenized at $4^{\circ} \mathrm{C}$ and a total protein extraction kit was used for protein extraction. A Coomassie brilliant Blue assay was used to determine the protein concentration to enable us to adjust the extracted protein from each group into the same concentration. The protein was then subjected to $10 \%$ denaturing polyacrylamide gel electrophoresis and transferred onto a polyvinylidene fluoride membrane blocked using $50 \mathrm{~g} / 1$ non-fat milk at room temperature for $1 \mathrm{~h}$. The proteins were then incubated with mouse anti-human p53 monoclonal antibody and concentrated rabbit anti-human $\beta$-actin monoclonal antibody, respectively, at $4^{\circ} \mathrm{C}$ overnight, followed by horseradish peroxidase-labeled goat anti-mouse IgG antibody at room temperature for $1 \mathrm{~h}$. Protein bands were visualized using a chemiluminescent kit and images were captured.

Statistical analysis. Data shown are the average of three experiments and are demonstrated as the mean \pm SD. SPSS software (version 16.0 for Windows, Chicago, IL, USA) was used for statistical analysis. Data were analyzed using one-way 
ANOVA, followed by a Student's two-tailed paired t-test for comparison between two groups. $\mathrm{P}<0.05$ was considered to indicate a statistically significant difference.

\section{Results}

Effects of rAd-p53 and radiation at various time points on cell viability. Our results demonstrated that a combination of rAd-p53 and radiation inhibited A549 cell growth in all groups, and cell viability suppression rates gradually increased from $0 \mathrm{~h}$-RT to $48 \mathrm{~h}$-RT (Table I). The cell viability suppression rates in the $6 \mathrm{~h}-\mathrm{RT}, 24 \mathrm{~h}-\mathrm{RT}$ and $48 \mathrm{~h}-\mathrm{RT}$ groups were $56.7 \pm 5.4$, $60.8 \pm 6.0$ and $68.9 \pm 6.6 \%$, respectively, which were statistically significantly higher than that of the Ad-p53 (40.8 \pm 4.7$)$, $0 \mathrm{~h}-\mathrm{RT}(45.0 \pm 3.5)$ and $3 \mathrm{~h}-\mathrm{RT}$ groups (47.0 \pm 4.3$)$. Additionally, no statistically significant differences were detected between the cell viability suppression rates of the $6 \mathrm{~h}-\mathrm{RT}, 24 \mathrm{~h}-\mathrm{RT}$ and $48 \mathrm{~h}$-RT groups $(\mathrm{P}>0.05)$.

Effects of rAd-p53 and radiation at various time points on cell apoptosis. Flow cytometry analysis revealed that the percentage of apoptotic cells gradually increased from $0 \mathrm{~h}-\mathrm{RT}$ to 48 h-RT (Table I; Fig. 2). The percentage of apoptotic cells in the $6 \mathrm{~h}-\mathrm{RT}, 24 \mathrm{~h}-\mathrm{RT}$ and $48 \mathrm{~h}-\mathrm{RT}$ groups were 39.7 \pm 5.4 , $42.9 \pm 6.6$ and $52.0 \pm 8.9 \%$, respectively, which were statistically significantly higher than that of Ad-p53 (9.2 \pm 2.7$), 0$ h-RT, $(30.1 \pm 5.4 \%)$ and $3 \mathrm{~h}$-RT groups (32.5 \pm 4.9$)$. Additionally, no statistically significant differences were detected in the percentage of apoptotic cells among the $6 \mathrm{~h}-\mathrm{RT}, 24 \mathrm{~h}-\mathrm{RT}$ and 48 h-RT groups $(\mathrm{P}>0.05)$.

Effects of rAd-p53 and radiation at various time points on $p 53$ protein expression. From $0 \mathrm{~h}-\mathrm{RT}$ to $48 \mathrm{~h}-\mathrm{RT}$ the $\mathrm{p} 53$ protein expression gradually increased (Fig. 3). The highest $\mathrm{p} 53$ protein expression level was detected in the Ad-p53 control group $(1.625 \pm 0.172)$, but it was not significantly different from that of the $48 \mathrm{~h}-\mathrm{RT}$ group $(1.590 \pm 0.211)(\mathrm{P}>0.05)$. The $\mathrm{p} 53$ protein expression level detected in the $6 \mathrm{~h}-\mathrm{RT}$ group $(0.856 \pm 0.092)$ was higher than that in $3 \mathrm{~h}-\mathrm{RT}$ group $(0.643 \pm 0.089)(\mathrm{t}=2.882$; $\mathrm{P}=0.045$ ), but not significantly different from that of the $24 \mathrm{~h}-\mathrm{RT}$ group $(1.193 \pm 0.202)(\mathrm{P}>0.05)$. A higher $\mathrm{p} 53$ expression was demonstrated in the Ad control group compared to that of the $0 \mathrm{~h}-\mathrm{RT}(0.509 \pm 0.105)$ and $3 \mathrm{~h}-\mathrm{RT}$ groups, however there was no statistical difference ( $\mathrm{P}>0.05)$ (Table I; Fig. 4). The A549 cell viability suppression rates of and percentage of apoptotic cells were positively correlated with $\mathrm{p} 53$ protein expression ( $\mathrm{P}=0.012, \mathrm{r}=0.87 ; \mathrm{P}=0.015$, $\mathrm{r}=0.85$, respectively) (Fig. 4). We did not detect the highest peak of $\mathrm{p} 53$ protein expression, which may be demonstrated $72 \mathrm{~h}$ following transfection.

\section{Discussion}

In the absence of DNA damaging factors, $\mathrm{p} 53$ protein expression is extremely low in cells, which maintains a wt-p53 protein half-life of 10-20 min through high turnover rate (15). The $\mathrm{C}$-terminus of the wt-p53 protein is capable of identifying and binding to damaged DNA bases or radiation-induced double-strand DNA breaks. This stabilizes the p53 protein and accumulates in the cells; wt-p53 half-life is extended to $1-2 \mathrm{~h}(16,17)$. Expression of the wt-p53 protein in tumor cells

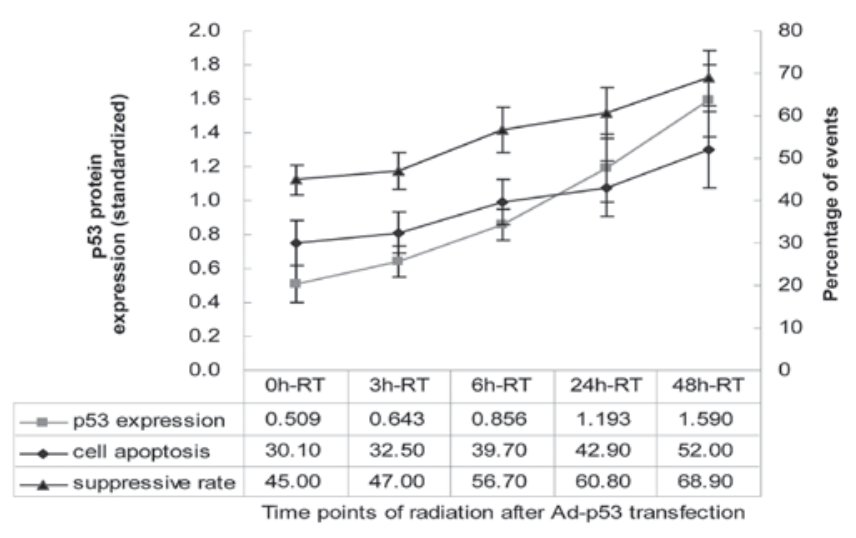

Figure 3. Correlation between p53 protein expression, cell viability suppression rates percentage of apoptotic cells. Ad, adenovirus.

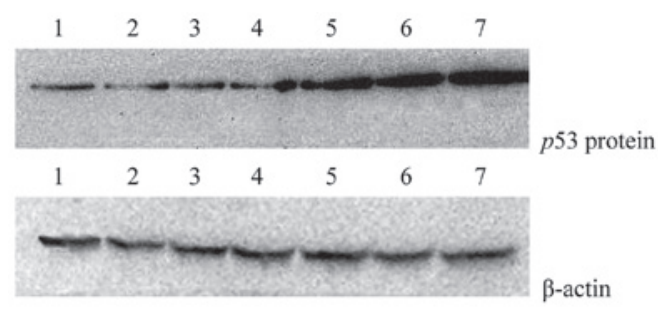

Figure 4. p53 protein expression at various radiation time points following rAd-p53 transfection. Lane 1, Ad control group; lane 2, 0 h-RT group; lane 3 , $3 \mathrm{~h}$-RT group; lane 4, 6 h-RT group; lane 5: 24 h-RT group; lane 6: 48 h-RT group; lane 7: Ad-p53 control group. rAd-p53, recombinant human adenovirus p53; RT, radiotherapy.

following Ad transfection may take a certain amount of time. Studies have demonstrated that $\mathrm{p} 53$ protein expression is initiated $3 \mathrm{~h}$ following rAd-p53 transfection, with an expression rate of approximately $50 \%$ at $12 \mathrm{~h}$ and a peak expression at 48-72 h (12-14). Based on these results, we selected a 72-h time point to detect all indicators following rAd-p53 infection. The present study revealed that $\mathrm{p} 53$ protein expression in the $0 \mathrm{~h}-\mathrm{RT}$ and $3 \mathrm{~h}$-RT groups was significantly lower than that of the $6 \mathrm{~h}-\mathrm{RT}, 24 \mathrm{~h}-\mathrm{RT}$ and $48 \mathrm{~h}-\mathrm{RT}$ groups $(\mathrm{P}<0.05)$, suggesting that radiation may affect p53 expression within a short period of time following rAd-p53 administration. This may be due to the decreased transfection power and/or the loss of the bystander killing effect of certain infected tumor cells, which were inhibited or killed by irradiation. Although the $48 \mathrm{~h}$-RT group had the highest level of $\mathrm{p} 53$ protein expression, it was not statistically different from that of the $6 \mathrm{~h}-\mathrm{RT}$ and $24 \mathrm{~h}-\mathrm{RT}$ groups $(\mathrm{P}>0.05)$. This also indicates that radiation greater than $6 \mathrm{~h}$ following rAd-53 transfection may have minimal effects on p53 protein expression.

Wt-p53 transfection may not only directly inhibit cell division and induce tumor cell apoptosis, but also has a bystander killing effect on tumor cells. Thus, wt-p53 gene therapy may also increase the sensitivity of tumor cells to radiotherapy and increase tumor cell susceptibility to apoptosis (18). This study demonstrated that in addition to the effect on $\mathrm{p} 53$ protein expression, radiation also affects p53-induced tumor cell apoptosis and cytotoxicity. In the $0 \mathrm{~h}-\mathrm{RT}$ to $48 \mathrm{~h}$-RT groups, the apoptotic rate of A549 cells gradually increased with prolonged rAd-p53 
action and interval of radiotherapy. The A549 cell viability suppression rates of the 6 h-RT, 24 h-RT and 48 h-RT groups were not significantly different, but were significantly higher than that of the immediate radiation and $3 \mathrm{~h}-\mathrm{RT}$ groups. This suggests that a combination of RT within $3 \mathrm{~h}$ of rAd-p53 administration is ineffective in causing sufficient synergistic cytotoxic effects on cancer cells. The A549 cell growth inhibition rate was positively correlated with p53 protein expression. The main mechanism of A549 cell growth inhibition in the 0 h-RT and 3 h-RT groups compared with the 6 h-RT, 24 h-RT and 48 h-RT groups may be that radiation reduces wt-p53 protein expression and decreases the radiation-sensitizing effect. Therefore, despite the above reasons leading to the decreased p53 protein expression and suppression of cell viability, a combination of rAd-p53 transfection into lung cancer cells and RT can be selected at 6-48 h following rAd-p53 transfection, rather than immediate to $3 \mathrm{~h}$. Otherwise, radiation may inhibit or damage p53 protein expression carried by the Ad and reduce its ability to directly kill tumor cells or indirectly sensitize them to irradiation.

In conclusion, radiation at various time points is able to affect p53 protein expression and cytotoxic effects of rAd-p53, and administration of RT at 6-48 h following rAd-p53 transfection may maximize the synergistic killing effect of these two treatments on tumor cells. The single high dose of radiation used in in vitro experiments may not accurately reflect the molecular biological changes caused by the conventional fractionated $2 \mathrm{~Gy}$ dose used in clinics. However, this study provides a theoretical basis for the reasonable arrangement of rAd-p53 transfection and radiotherapy interval, and further investigation is required.

\section{Acknowledgements}

This study was supported in part by a grant from the National Natural Science Foundation of China (\#30700979) and Science and Technology Project of Shenyang (\#110492) to Dr Cheng-Bo Han.

\section{References}

1. Vousden KH and Lu X: Live or let die: the cell's response to p53. Nat Rev Cancer 2: 594-604, 2002.

2. Hirao A, Kong YY, Matsuoka S, Wakeham A, Ruland J, Yoshida H, Liu D, Elledge SJ and Mak TW: DNA damage-induced activation of $\mathrm{p} 53$ by the checkpoint kinase Chk2. Science 287: 1824-1827, 2000.
3. Huang CL, Yokomise $\mathrm{H}$ and Miyatake A: Clinical significance of the p53 pathway and associated gene therapy in non-small cell lung cancers. Future Oncol 3: 83-93, 2007.

4. Kandioler D, Stamatis G, Eberhardt W, Kappel S, Zöchbauer-Müller S, Kührer I, Mittlböck M, Zwrtek R, Aigner C, Bichler C, et al:. Growing clinical evidence for the interaction of the p53 genotype and response to induction chemotherapy in advanced non-small cell lung cancer. J Thorac Cardiovasc Surg 135: 1036-1041, 2008.

5. Kandioler D, Zwrtek R, Ludwig C, Janschek E, Ploner M, Hofbauer F, Kührer I, Kappel S, Wrba F, Horvath M, et al: TP53 genotype but not p53 immunohistochemical result predicts response to preoperative short-term radiotherapy in rectal cancer. Ann Surg 235: 493-498, 2002.

6. Shiomitsu K, Sajo E, Xia X, Hunley DW, Mauldin GE, Li S and Mauldin GN: Radiosensitivity of canine osteosarcoma cells transfected with wild-type p53 in vitro. Vet Comp Oncol 6: 193-200, 2008.

7. Gudkov AV and Komarova EA: The role of p53 in determining sensitivity to radiotherapy. Nat Rev Cancer 3: 117-129, 2003.

8. Cuddihy AR and Bristow RG: The p53 protein family and radiation sensitivity: yes or no? Cancer Metastasis Rev 23: 237-257, 2004

9. Takahashi T, Fukawa T, Hirayama R, Yoshida Y, Musha A, Furusawa Y, Ando K and Nakano T: In vitro interaction of high-LET heavy-ion irradiation and chemotherapeutic agents in two cell lines with different radiosensitivities and different p53 status. Anticancer Res 30: 1961-1967, 2010.

10. Takahashi A, Matsumoto H, Yuki K, Yasumoto J, Kajiwara A, Aoki M, Furusawa Y, Ohnishi K and Ohnishi T: High-LET radiation enhanced apoptosis but not necrosis regardless of p53 status. Int J Radiat Oncol Biol Phys 60: 591-597, 2004.

11. Pan JJ, Zhang SW, Chen CB, Xiao SW, Sun Y, Liu CQ Su X, Li DM, Xu G, Xu B and Lu YY: Effect of recombinant adenovirus-p53 combined with radiotherapy on long-term prognosis of advanced nasopharyngeal carcinoma. J Clin Oncol 27: 799-804, 2009.

12. Roth JA: Adenovirus p53 gene therapy. Expert Opin Biol Ther 6: 55-61, 2006.

13. Ma JT, Zheng W and Zou HW: Radiosensitivity enhanced by recombinant adenovirus p53 in lung adenocarcinoma. Journal of China Medical University 36: 424-426, 2007.

14. Ma G, Kawamura K, Li Q, Suzuki N, Liang M, Namba M, Shimada $\mathrm{H}$ and Tagawa M: Cytotoxicity of adenoviruses expressing the wild-type p53 gene to esophageal carcinoma cells is linked with the CAR expression level and indirectly with the endogenous p53 status. Cancer Gene Ther 16: 832-840, 2009.

15. Ashcroft M, Kubbutat MH and Vousden KH: Regulation of p53 function and stability by phosphorylation. Mol Cell Biol 19: 1751-1758, 1999.

16. Reed M, Woelker B, Wang P, Wang Y, Anderson ME and Tegtmeyer P: The C-terminal domain of p53 recognizes DNA damaged by ionizing radiation. Proc Natl Acad Sci USA 92: 9455-9459, 1995.

17. Lakin ND and Jackson SP: Regulation of p53 in response to DNA damage. Oncogene 18: 7644-7655, 1999.

18. Gudkov AV and Komarova EA: Prospective therapeutic applications of p53 inhibitors. Biochem Biophys Res Commun 331: 726-736, 2005. 